$307-315$

\title{
太湖平原圩区分类及圩区洪涝分析 以湖西区为例
}

\author{
高俊峰 \\ 毛-筥 \\ (中国科学院南京地理与神泊研究所, 南京 210008)
}

$P 333 \cdot 2$

\begin{abstract}
提要以太湖平原湖酉区为例，用聚类分析，对圩区进行了分类。结合地形条件，把圩分成 3 大类，8 小类。并对扜区致满原因进行了分析。结果表明; 雨量、水面率、田面高程、排㳻能力、扜塨高 度、地形等是致涝主要原因。结台产流原理、设计三口不同降雨量，引入一分级指标 $M$,对每一类 扜的洪渀危险思度进行了分析计算,得出每一类圩在不同设计雨量下的危险程度. 主要结论是: 扜 区受淓.更多的是人类活动的影响，地形高处不一定比地形低处安全 3 抽排能力不足和木面率小是 扜内致满的主要原因。
\end{abstract}

关镜词圩圩的分类逪满危险度，

\section{一、前}

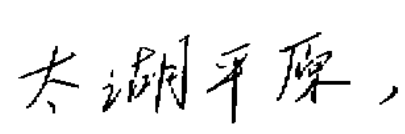

议区，召

太湖平原是长江三角洲的一冲积平原，面积 $35,272.4 \mathrm{~km}^{2}$ 。西以茅山山脉与界岭为界， 南以钱㙈江为界, 北以长江为界, 东临东海。沿江、沿海地区由于受泥沙冲湤的影响, 形成一 相对较高的环形“岗身”地带、以太湖为中心的中问地区是一相对低仙地区。所以太湖平原是 一“碟形洼地”。平原内湖荡众多、水网密布, 通江贯海, 富庶发达。太湖平原地势低洼和其 忧越的地理位置, 水土资源及气象条件, 极适合人类生活、生产。已在国民经济中显示出越来 越显要的地位。与长江中下游的其他平原地区一样, 太湖平原千百年来一直迴受洪水的威 胁。据历史考察, 筑圩始于春狄时, 吴在固娍湖区筑圩, 变涂泥“为吴之沃土” 2400 年。太湖地区的圩田,大约形成于唐后期, 发展和巩固于五代吴越时期。北宋以后开始 紊乱, 明清以后至解放前, 日益寗坏。

圩是古代荡动人民与自然外争的结果，圩在抗御洪水过程中发挥了巨大作用。目前对圩 的研究主要有: 圩区洪涉治理的定性尔析; 用非线性规则的方法研究圩区最优水面率及抽

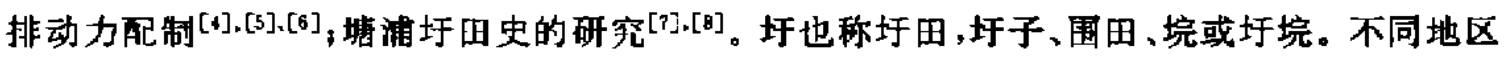
有不同称谓。它是利用地形, 或沿自然河道,堆土做堤; 或开挖河沟, 围田筑堤; 或与山丘连 接, 背山处筑堤闱田。平原地区,圩堤一般是闭合的,有节制闸或抽排水站进行圩内水量与扞

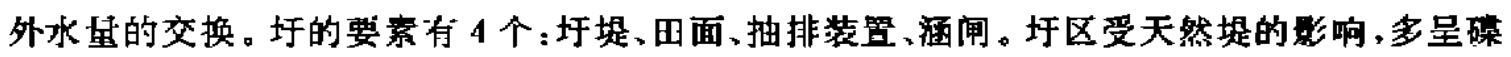
形。其主要特点是: 水高田低; 洲期或汗期某一段时间, 圩外河网水位高于圩内田面高程。决 定圩是否受淽的因素有 4 个: (1)圩堤高度是否高于外河水位,圩堤是否能承受水力不破堤;

本文于 1993 年 3 月 B 日收到, 6 月 7 日改回.

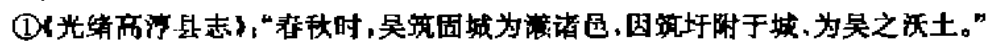


(2)抽排动力是否能排除圩内嘴水; (3)圩内田面相对高程; (4)圩内水面率大小。

本文选择太湖平原湖西区作为典型来研究圩区分类及洪涉危险圩的划你。这里地形条 件复杂且各种类型的圩在此均有。

\section{二、坶的分类}

\section{1. 资料的处理}

不同地形条件下圩的受劳机制不同，考虑到圩是一相对独立体，其所处地形条件对其受 满程度影响甚大。现有圩的资料不能反映地貌差异特征。根据圩在地形图上的具体位置判 读。圩的类型及判别标准是：

（1）半山圩 这种圩临河傍山, 部分为山丘坡地, 部分为低洼圩田。圩田与外河有一圩堤 相隔。

(2)平坦圩 这种圩位于平坦洼地,高差起伏不大, 四面间高差一般在 $1 \mathrm{~m}$ 之内, 圩内河 网水位基本一致。某一级四面高程所占面积 $\geqslant 71 \%$ 。

(3)高差圩这种圩介于半山圩和平坦圩之间, 田面有朋显高差, 但高差一般不超过 $1.5 \mathrm{~m}$ 。某两级田面高程不同的田面积之和占圩总面积的 $80 \%$ 以上。

按上面三种类型将湖西区圩 (面积 $\geqslant 200 \mathrm{hm}^{2}$ ) 分成三大类: 半山圩 13 个: 平坦圩 45 个， 高差㘧 18 个。

综合圩区的资料来看，圩堤高度、水面率(圩内水面积与圩的总面积比值)、排满模数（排 步流量与圩内总面积的比值)、田面相对高程 (四面高程与洲前圩内平均水位差),这四个要 䇣与圩的受满程度密切相关。本文用以分析的原始资料表见表 $1 、 2 、 3$ 。

表 1 半山扜原始突料

Tab. 1 Data of polders by hills

\begin{tabular}{|c|c|c|c|}
\hline 学 早 & 水面率 & $\begin{array}{c}\text { 排水模教 } \\
\left(\mathrm{m}^{2} / \mathrm{s} \cdot \mathrm{hm}^{2}\right)\end{array}$ & $\begin{array}{c}\text { 田面相对高理 } \\
\text { (m) }\end{array}$ \\
\hline 1 & 0.18 & 0.0080 & 0.76 \\
\hline 2 & $0 . \infty 9$ & 0.0036 & 1. 10 \\
\hline 3 & 0.11 & 0.0092 & 0.51 \\
\hline 4 & 0.09 & 0.0047 & 0.72 \\
\hline 5 & 0.26 & 0.0079 & 1.20 \\
\hline 6 & 0.07 & 0.0043 & 2.05 \\
\hline 7 & 0.10 & 0.0070 & I. 40 \\
\hline B & $0.0 B$ & 0.0049 & 1.54 \\
\hline 9 & 0.15 & 0.0072 & $0.9 B$ \\
\hline 10 & 0.07 & 0.0046 & 0.73 \\
\hline 11 & 0.09 & 0.0034 & 0.76 \\
\hline 12 & $0.0 B$ & 0.0078 & 0.92 \\
\hline 13 & 0.11 & 0.011 & 1.08 \\
\hline
\end{tabular}

表 2 高差圩原始宾料

Tab. 2 Data on mixed high land polders

\begin{tabular}{|c|c|c|c|}
\hline 宇 寻 & 水面率 & $\begin{array}{c}\text { 排水阵效 } \\
\left(\mathrm{m}^{2} / \mathrm{s} \cdot \mathrm{hm}^{2}\right)\end{array}$ & $\begin{array}{c}\text { 田面相对踾 } \\
\text { (m) }\end{array}$ \\
\hline I & 0.17 & 0.0060 & 0.33 \\
\hline 2 & 0.08 & 0.0026 & I. $7 \theta$ \\
\hline 3 & 0.14 & 0.0046 & I. 20 \\
\hline 4 & 0.10 & 0.0047 & 1. 10 \\
\hline 5 & 0.05 & 0.0077 & 0.90 \\
\hline 6 & 0.07 & 0.0064 & 0.90 \\
\hline 7 & 0.15 & 0.0046 & 1.05 \\
\hline 8 & 0.14 & 0. 0024 & 1. 70 \\
\hline 9 & 0.11 & 0. 0050 & a. 65 \\
\hline 10 & 0. 17 & 0.0074 & 0. 32 \\
\hline 11 & 0. 17 & 0. 0094 & 0.99 \\
\hline 12 & 0.13 & 0.011 & a. 99 \\
\hline 13 & 0.13 & 0.012 & 1.30 \\
\hline 14 & 0.14 & 0.014 & 1. 74 \\
\hline 15 & 0.15 & 0. $007 \mathrm{~B}$ & a. 94 \\
\hline 16 & 0. 08 & 0.0079 & 0.70 \\
\hline 17 & 0. 19 & $0.01 \mathrm{~J}$ & 1. 10 \\
\hline $1 B$ & 0. 08 & $0.009 \mathrm{~B}$ & 1. 34 \\
\hline
\end{tabular}


表 3 平坦圩原始资料

Tab. 3 Data on flat land polders

\begin{tabular}{|c|c|c|c|c|c|c|c|}
\hline 序昂 & 水面事 & $\begin{array}{c}\text { 振水喵数 } \\
\left(\mathrm{m}^{3} / \mathrm{s} \cdot \mathrm{hm}^{2}\right)\end{array}$ & $\begin{array}{c}\text { 田面相对京程 } \\
\text { (m) }\end{array}$ & 序 㝵 & 水面本 & $\begin{array}{c}\text { 排水模数 } \\
\left(\mathrm{m}^{2} / \mathrm{s} \cdot \mathrm{hm}^{2}\right)\end{array}$ & $\begin{array}{c}\text { 田面相对满程 } \\
\text { (m) }\end{array}$ \\
\hline 1 & a. 04 & 0.0096 & 0.65 & 2 & 0.08 & $0 . \overline{014}$ & 1.21 \\
\hline 3 & 0.08 & 0. 0094 & 1.10 & 4 & 0.22 & 0.0059 & 0.58 \\
\hline 5 & 0.19 & 0.0078 & 0. 90 & 6 & 0.09 & 0.0077 & 1.05 \\
\hline 7 & 0.07 & 0.0075 & 0.10 & 8 & 0.03 & 0.011 & 0.73 \\
\hline 9 & 0.04 & 0.0039 & 1.44 & 10 & 0.29 & 0.0073 & 0.69 \\
\hline 11 & 0.05 & 0.011 & 0. 72 & 12 & 0.06 & 0.0062 & 1. 00 \\
\hline 13 & 0.09 & 0.0035 & 0.90 & 14 & 0.08 & 0.0045 & 0. 90 \\
\hline 15 & 0.21 & 0.0090 & 0.80 & 16 & 0.10 & 0. 0029 & 1.00 \\
\hline 17 & a. 11 & 0.014 & 0.31 & 18 & 0.10 & 0.0086 & 1. 30 \\
\hline 19 & 0. 24 & 0.0078 & 1. 25 & 20 & 0.11 & 0.0093 & 1. 36 \\
\hline 21 & a. 14 & 0.0061 & 1.00 & 22 & 0.15 & 0.011 & 0.98 \\
\hline 23 & 0.08 & 0.0056 & 1.04 & 24 & 0.05 & 0.012 & 0.79 \\
\hline 25 & 0.08 & 0.0079 & 0. 89 & 26 & 0.08 & 0.0079 & 0.89 \\
\hline 27 & 0.15 & 0.0088 & 0.8 .3 & 28 & 0.11 & 0.011 & 0.68 \\
\hline 29 & 0.07 & 0.012 & 1. 02 & 30 & 0.06 & 0.0096 & I. 07 \\
\hline 31 & 0.09 & 0.0090 & 0.71 & 32 & 0.13 & 0.0073 & 1.42 \\
\hline 33 & 0.16 & 0.0081 & 0.58 & 34 & 0.08 & 0.0080 & 0.75 \\
\hline 35 & 0.17 & 0.0060 & D. 33 & 36 & 0.12 & 0.0053 & 1. 00 \\
\hline 37 & 0.07 & 0.011 & 0.49 & 38 & 0.09 & 0.010 & 0.69 \\
\hline 39 & 0.17 & 0.0086 & 0.82 & 40 & 0.08 & 0.0075 & 0.72 \\
\hline 41 & 0.12 & 0.0086 & 0.80 & 42 & 0.01 & 0.0054 & 0.90 \\
\hline 43 & 0.08 & 0.010 & 0.78 & 44 & 0.11 & 0.0082 & 0.42 \\
\hline 45 & D. 26 & 0.014 & 0.70 & & & & \\
\hline
\end{tabular}

\section{2. 分类方法}

根据聚类分析的分类思想，属性或特拄相似的圩必然聚到同一类之中。对于圩来说，其 出现的那一天起就与抗御洪港联系在一起，圩资料所反映的信息必然也反映其抗御洪漟的 强弱，聚类分析即通过对资料的处理，将具有相同或相似抗御洪涝特性的圩分到一类中。

为了消除所选择要素的量纲对你类的影响,首先将表 $1 、 2 、 3$ 中的数据按 (1)式标准化。 经此变换后的数据, 其均值为零, 标准差为 1 ,且与变量的量纲无关。

$$
\begin{gathered}
x^{\prime}{ }_{1}=\frac{x_{1}-\overline{x_{2}}}{S_{j}} \\
\overline{x_{j}}=\frac{1}{n} \sum_{i=1}^{0} x_{1 j} \\
s_{j}=\left[\frac{1}{n-1} \sum_{i=1}^{\infty}\left(x_{1}-\overline{x_{j}}\right)\right]^{1 / 2} \quad(i=1,2 \cdots, n ; j=1,2 \cdots, m)
\end{gathered}
$$

式中, $n$ 为样本数 (每类圩中圩的数量); $m$ 为圩的要㬌个数; $x_{1}$, 为原始数据; $x^{\prime},$, 为经 标准化后的数据。

圩之问的“亲疏”程度一一距离，用欧氏距离来计算：

$$
\left.D_{i j}=\left[\sum_{k=1}^{n} x_{1 k}-x^{\prime} j_{k}\right)^{2}\right]^{1 / 2} \quad(k=1,2,3, \cdots \cdots m)
$$

式中: $x^{\prime}{ }_{k k}$ 为第 $i$ 个圩子的第 $k$ 个要美值; $x^{\prime}, k$ 为第 $j$ 个圩子第 $k$ 个要素值; $i, j$ 为任意 两个圩; $D_{i j}$ 为圩 $i$ 和 $j$ 之间的距离。 
离差平方和法基于方差你析的思想，即如果类分得合理，则同类圩之间离差平方和应当 最小、类与类之间的离差平方和应当较大。基于这样的理论，先使n个圩子自成一类,然后将 其中两个合并成一类, 再合并其中两类、照此做下去,直到所有样品旧为一类为此 ${ }^{[9]}$ 。假设已

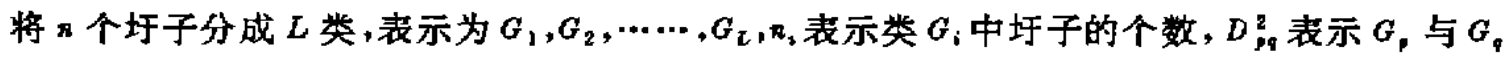
之间的距离, 则类 $G_{,}$与 $G_{q}$ 合并成新类 $G_{\mathrm{r}}=\left\{G_{,}, G_{q}\right\}, G_{\mathrm{r}}$ 与任一类 $G_{i}$ 的距离道推公式为:

$$
D_{r}^{2}=\frac{n_{i}+n_{2}}{n_{r}+n_{i}} D_{i j}^{2}+\frac{n_{i}+n_{q}}{n_{r}+n_{i}} D_{w}^{2}-\frac{n_{2}}{n_{r}+n_{i}} D_{m q}^{2}
$$

离差平方和法是单调的，该方法能得到局部最优解。

\section{3. 分类结果:}

用上述分类方法,将半山圩分成二类: $k_{1}-1$ 和 $k_{1}-2$ 类。 $k_{1}-1$ 类包括 $(1,9,3,5,7,8), k_{1}-2$ 类包括 $(2,4,10,11,6,12,13)$; 将高差圩分成三类: $k_{2}-1, k_{2}-2$ 和 $\mathbf{k}_{2}-3$ 。 $k_{2}-1$ 包括 $(2,8,4,16$ ， $3,7,9,5,6), k_{2}-2$ 包括 $(11,15,17,12,13,14,18)$ 。 $\mathrm{k}_{2}-3$ 类包括 $(1,10)$; 将平坦圩分成三类: $k_{3}-1, k_{3}-2, k_{3}-3 。 k_{3}-1$ 类包括 $(1,8,11,2,18,20,3,30,6,25,26,10,24,32) ; k_{9}-2$ 类包括 (4, $19,45,9,17,44,36,28,22) ; \mathrm{k}_{3}-3$ 类包括 $(5,15,37,7,35,43,12,23,42,13,14,16,27,39,38$, $21,29,41,33,31,34,40$ )。圩的聚类竹类噌系见图 1、2、3。每一类圩的具体位置见图 4。

聚类分析将具有相似特点的圩仔到同一类之中, 它们在防洪抗茄中有共同特性。

\section{三、圩区洪涝分析}

太湖平原广大圩区,地形平坦，地势低连。圩区受圩堤影响，四周高、中间低。汛期䅗雨

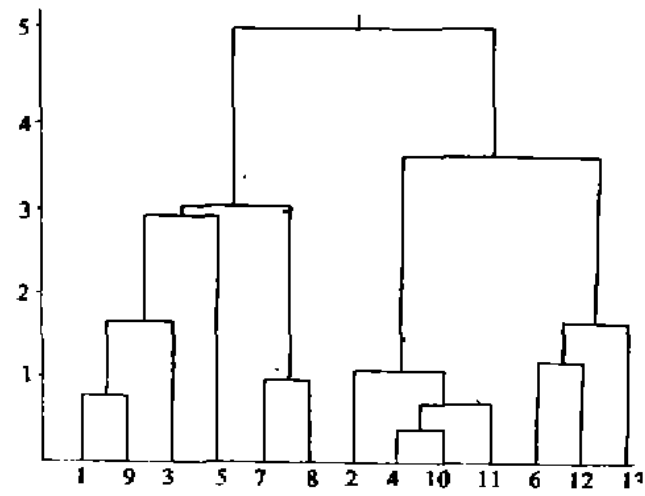

图 1 半山圩聚类详系图

Fig. 1 Cluster figure of polders by hills

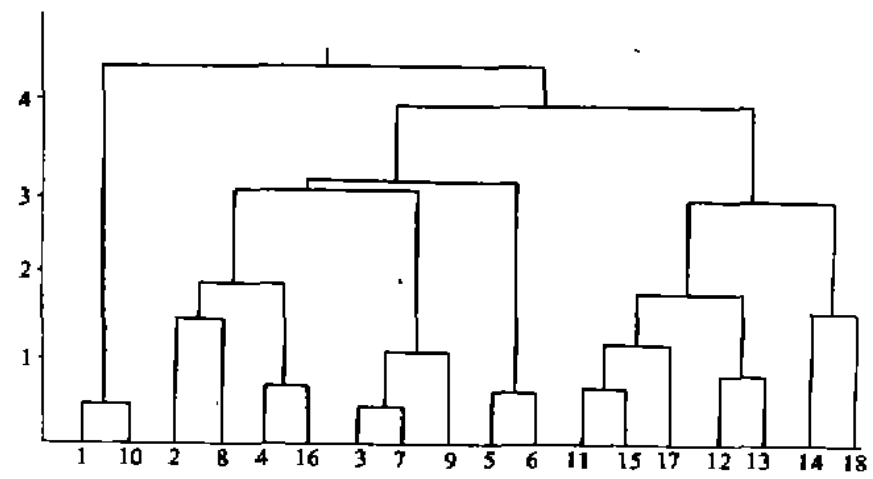

图 2 高差圩聚类璔系图

Fig. 2 Cluster figure of mixed high land polders

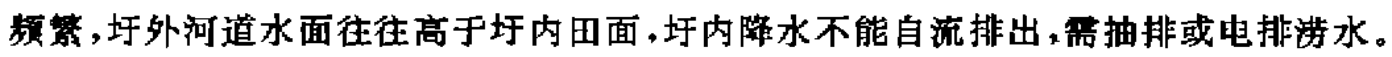

圩区致洪有以下 6 种情况:

1. 降雨至大 造成本地区成满的雨型有两种,一种是梅雨、二是台风雨。1954、1991 年 洪水就是梅雨型。梅雨季节在 6.7 月, 梅雨期一般长约 20 天,最长达 63 天 (1965 年)。梅雨 期降雨量约占全年降雨量的一半左右, 降雨形式多连绵阴雨,偶有阵雨和暴雨。1954年全流 域降水较均匀, 5-7 月降水 $891 \mathrm{~mm}$, 为多年平均的 1.57 倍、降水激率 50 年一遇。1991 年降 


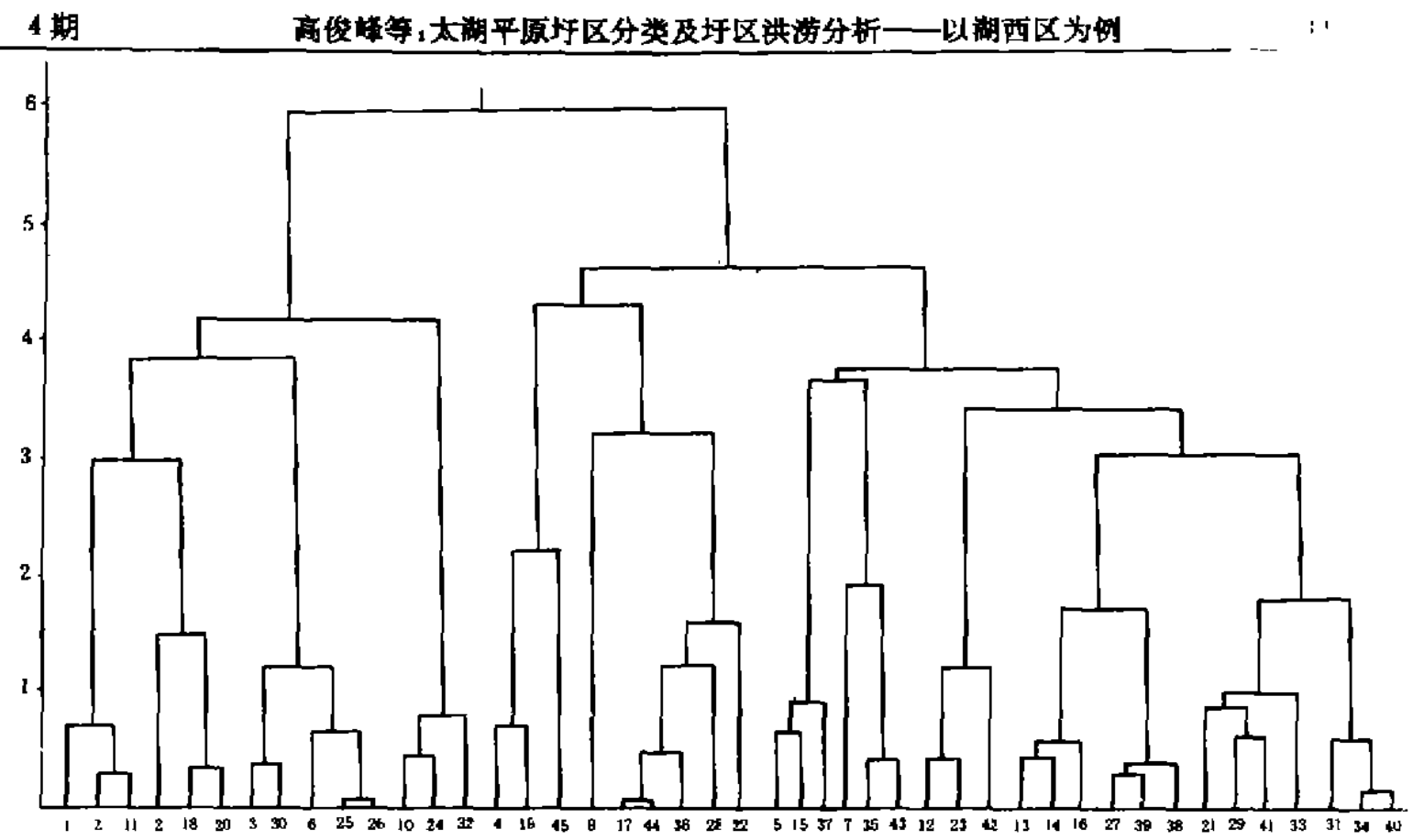

[ㄱ 3 平坦扜聚类谱系泈

Fig. 3 Cluster figute of flat land polders

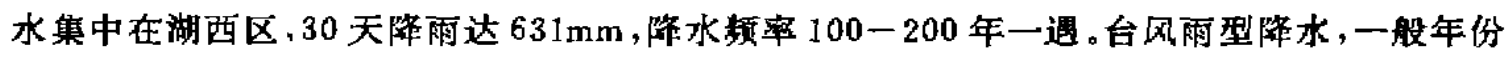
7 月中们至 9 月中们在太平洋上形成台风, 在我国东南沿海登陆后, 北上穿过本流域。以 1962 年 9 月 4-6 日洪水为典型, 该次洪水由 14 号台风形成, 暴雨中心在常熟、苏州、嘉兴 一坓, 其中苏州雨量达 $438.8 \mathrm{~mm}$ 。引起河网本位两天内暴胀 0.75-1.16 $\mathrm{m}$ 。这两种类型降本 对该区造成严重洪港威胁。

2. 圩外水面高于圩内田面 太湖平原周边高程 5-6m, 中间 $0.5-3.5 \mathrm{~m}$, 高差约 $2.5 \mathrm{~m}$ 。 中间洼地包括淀泖、青松、嘉北，是最易发生洪涉灭害的地方。太湖平原位于长江和钱塘江河 口段,河流比降十分平缓,达 $1 / 10^{5}-2 / 10^{5}$ 。平原上虽然河道纵横、到处见水，但流速很慢、经 常维持 $0.1-0.2 \mathrm{~m} / \mathrm{s}$, 泄本能力很小, 一遇洪本即衰积不肠。太湖流域紧菲东海, 河道受潮沙 顶托影响，使洪水排泄更加受阻。这些因宗都导致汛期圩外河网本位陡洗，再加河网之间圩 区大量港水抽排出来,使圩外水位高过圩内田面高程。

3. 圩区调害水面不足 自从 1954 年以来,太湖流域进行过大规模的湖泊围圼及圩区改 造工程。在一些低洼农田都修建了大大小小的圩区，同时还联圩、并圩而发展成控制性的大 包围。近 20 年来,太湖平原圩外水面减少了 $650 \mathrm{~km}^{2}$ ，占原太湖平原总圩外本面的 $26 \%$ 。河 湖调亩容积减少近 $10 \times 10^{\mathrm{\theta}} \mathrm{m}^{3}$ 。其中湖西区调亩本面积减少最多、比 60 年代减少 $42 \%$ 。太湖 调富容积比 60 年代城少 $2 \times 10^{8} \mathrm{~m}^{3}$ 以上。结果是遇到较大洪水时,圩外河湖水位急剧升离, 持续时问又长，增加了河湖防洪压力。同时，圩区有些水面已开辟成为精养鱼池，是为水面， 却对水深、水位及变幅有严格要求,过量的水要排出池，水深不足还要补充注水。这种梢养鱼 池没右畄漟功能，不能充当圩区水面率，也是治满的一种负担。在长江流域规划中 (1988 年) 提出以 $10 \%$ 的内湖水面率作为中下游平原圩区治㳻的基础。据太湖平原圩区来看, 大部分 圩内水面率都超过了这个标准，也有一部分圩的内本面率没有达标，这些圩主要是半山圩。 


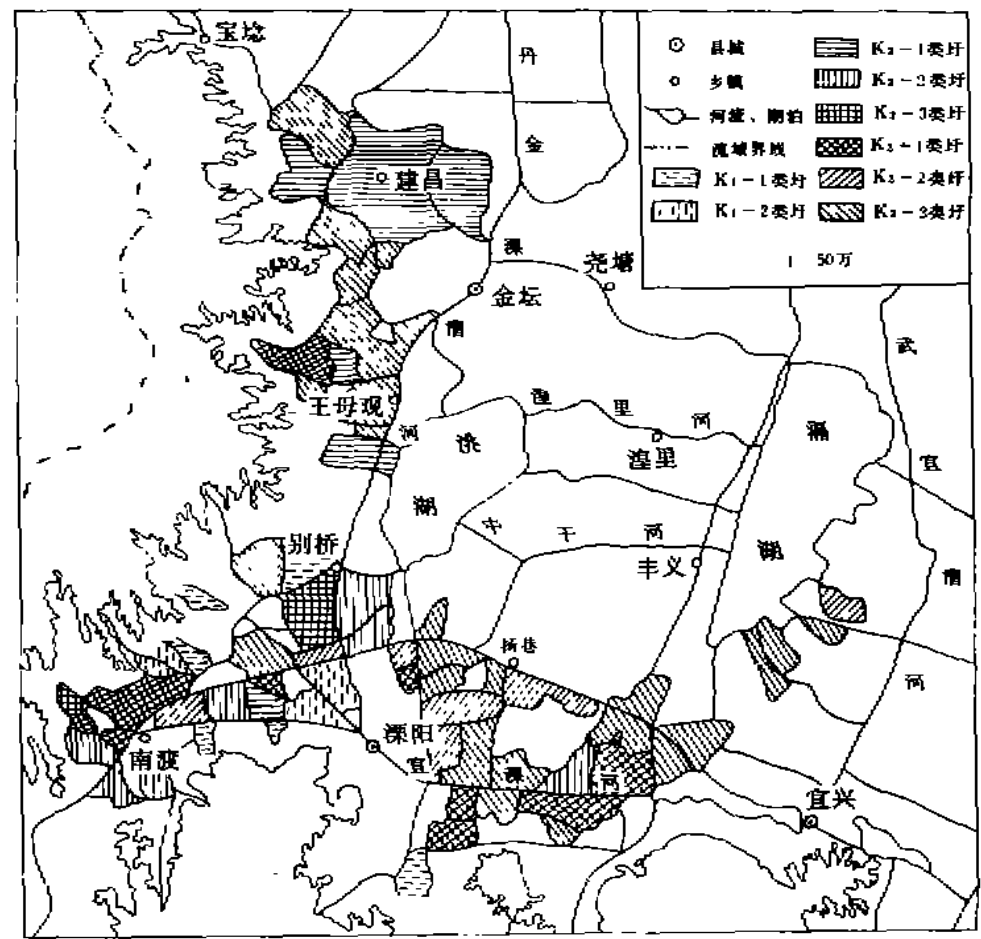

图1坶子分荷图

Fig. 4 Distribution of polders

4. 圩区排水装机不足或配夶工程不完备 圩区排苏发展有如下几个阶段: 自流排洪; 内 湖与酒闸并举; 涵闸、内湖与渠系并举; 机电排水泉的应用。目前太湖平䝠圩区排涝标准下限 (排漠模数 $\mathrm{m}^{3} / \mathrm{s} \cdot \mathrm{hm}^{2}$ ) 为 $0.005 \mathrm{~A}$ 。太湖平原不同的地区对装机容量有不同的规定，一般按 日雨 150-200 $\mathrm{mm}, 2-3$ 天排出来设计排满能力。1954 年洪水敲响了瞥钟。各地水利条件郬 有不同珪度的改善。治理重点集中在下游低洼地区, 忽椙上游湖西地区及长兴的治理。湖西

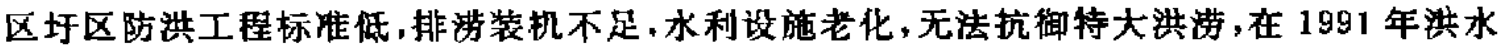
中,破圩块堤多, 海没范围大, 灾情严重。太湖平原的几片半高地, 由于高程相对较高, 排水能 力和水利设施防洪标准也很低。发生洪涝吋反面成了受茜区。1991 年洪水即如此。

5. 圩堤未达标准 汛期圩外河网水位一般较高, 圩堤是圩内耕地及生产免受涝灾的主 要设施。太湖平原的地形大致由西向本倾斜，且周边高、中问低，各地的圩堤高度不同。圩堤 的高度一般以 1954 年洪水位作为设计标准。1954 年以来,河网、湖泊等地面状况纮发生了 变化，其蓄水能力普遍减小,虽然增加了抽排设施,但如果发生 1954 年型洪水,其水位也比 1954 年实测水位要高。1954 年是有记录以来太湖平原最大洪水,频率为 50 年一遇。1991 年 洪水全流域只为 25 年一遇。平原内实测到的水位, 湖西及太湖水位超过 1954 年，其它地区 与 1954 年水位相比,差距在 $0-35 \mathrm{~cm}$ 之问。丹阳、金坛、常熟、宜兴都有因圩堤高度不的面 破圩的情况。

6. 地形致涝 太湖平原西部山地分布的半圩区,临山一面不修圩堤,临水一面修堤与山 连接。降雨时,圩内成了一集水的水库, 山坡上降水向圩内汇集, 虽然有吋圩外水位相对较 低，但内涝已构成威胁。在平原下游的低注地区还行布旁 $3.5-4.0 \mathrm{~m}$ 以上的半高地，因其地 势洛高，一般洪水不成灾，其圩区建设标准低且不配套，汛期外河水位猛张，这些相对较高的 
扞因防洪标准低河受涝。地形起伏不大的圩，如果没有采取高水高排，低水低排，降雨吋高处 水迅速向低处汇集,也会使低处受淽。

\section{四、危险圩的划分}

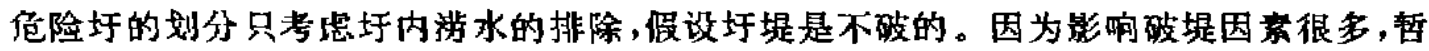
不做考䍐。

在以下前提下分析洪涉危险圩:

1、㘪内产流以蓄满产流计算。

2. 计算水四的起始水深为水招四适宜水深上限，末了水深取酎淹水深上限，计算吋问取 水程丞橞期。(其它吋期或水深只需变动相应参数,类似计算。)

3. 设计三日路雨,排水吋间 1 天, 每天开机 $22 \mathrm{~h}$ 。

引人一洪涉你险扞分级指标 $M$, 它综合了圩内产流及圩本身的特性：

$$
\begin{gathered}
M=\frac{\triangle H}{W \cdot T \cdot 22 \cdot 3600} \\
\triangle H=R-a \cdot H \cdot x
\end{gathered}
$$

排淽天数 $T$ 取 4 天, $(6)$ 式简化为

$$
M=31.58 \cdot \triangle H / W
$$

式 $(6)-(8)$ 中， $M$ 为危险圩分级指标; $R$ 为圩内降雨净雨深 $(\mathrm{m}) ; W$ 为排堂模数 $\left(\mathrm{m}^{3} /\right.$ $\left.\mathrm{s} . \mathrm{hm}^{2}\right) ; \chi$ 为水面率; $I I$ 为四面相对高程; $a$ 为经验系数。

四面相对高屋取四面分级高程的加权平均值。设某一个扞的四面高程为 $x_{1}-x_{2}, x_{2}-$ $x_{3} \cdots \cdots, x_{n-1}-x_{n}, x_{n}-x_{n+1}$, 相应分级面积分别为 $\mathrm{A}_{1}, \mathrm{~A}_{2}, \cdots, \cdots, \mathrm{A}_{n}$ 。则

$$
I=\frac{\left(x_{1}+x_{2}\right) A_{1}+\left(x_{2}+x_{3}\right) A_{2}+\cdots \cdots+\left(x_{n}+x_{n+1}\right) A_{2}}{2 A}-h
$$

式中 $h$ 为圩内汛前平均水位 $(m)$ 。

a值是用 1991 年湖西区实际的降雨和洪港炎菑资料,并且结合地形图高程不同四面所 占比例来确定。半山圩 $\alpha$ 为 0.33 ，高差圩 $a$ 为 0.5 ; 平坦圩 $\alpha$ 为 0.67 。当用这些参数吋, 1991 年受溇圩有 $95 \%$ 以上与计算判别相符。

\begin{tabular}{|c|c|c|c|}
\hline 扞的类型 & 水面育 & 排水模数 $\left(\mathrm{m}^{3} / \mathrm{s} \cdot \mathrm{hm}^{2}\right)$ & 田面相对高保(m) \\
\hline$k_{1}-1$ & 0.100 & 0.0076 & 0. 350 \\
\hline $\mathbf{k}_{1}-2$ & 0.150 & 0.0110 & 0. 330 \\
\hline $\mathbf{k}_{2}-1$ & 0.120 & 0.0043 & 0.550 \\
\hline $\mathbf{k}_{2}-2$ & 0.167 & 0.0110 & 0.700 \\
\hline $\mathbf{k}_{2}-\mathbf{3}$ & 0.170 & 0.0067 & 0.325 \\
\hline $\mathbf{k g}_{\mathbf{3}}-1$ & 0.100 & 0.0100 & 0.660 \\
\hline$k_{3}-2$ & 0.160 & 0.0100 & 0.600 \\
\hline$k_{3}-3$ & 0.100 & 0.0076 & 0.530 \\
\hline
\end{tabular}

$W, x, H$ 取每类扞的平均值。见表 4 。

表 1 各类圩要亲平均值

Tab. 1 Mcan valus of factors of polders 
设计三日降雨量、分别计算每一类圩内三种不同下垫面: 水面、水程田, 旱地非耕地的产

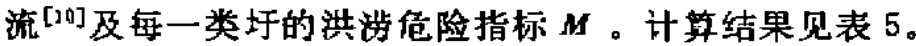

表 5 各类扜在不同设计降雨量下的和 $M$

Tab. 5 Flood risk extent $M$ of every polder based on design rainfall

\begin{tabular}{|c|c|c|c|c|c|c|c|c|c|c|c|}
\hline \multirow{2}{*}{$\begin{array}{c}\text { 旪计三日 } \\
\text { 妕雨(cm) }\end{array}$} & \multicolumn{3}{|c|}{ 净雨深(回) } & \multicolumn{8}{|c|}{ 危险指标 $\boldsymbol{M}$} \\
\hline & 水面 & 水田 & 早地 & $K_{1}-1$ & $\mathbf{K}_{1}-2$ & $\mathbf{K}_{2}-1$ & $k_{t}-2$ & $K_{2}-3$ & $K_{3}-1$ & $\mathrm{~K}_{3}-2$ & $\mathrm{~K}_{3}-3$ \\
\hline 340 & 0. 330 & 0.328 & 0.290 & 1.752 & 1.122 & 2.775 & 0.835 & 1. 862 & 1.172 & 1.043 & 1.650 \\
\hline 330 & 0.320 & 0.318 & 0. 280 & 1.690 & 1.081 & 2. 665 & 0.793 & 1.792 & 1. 125 & 0.997 & 1. 588 \\
\hline 320 & 0.310 & 0.308 & 0.270 & 1.628 & 1.039 & 2. 555 & 0.752 & 1.721 & 1.079 & 0.950 & 1.525 \\
\hline 310 & 0.300 & 0.298 & 0.260 & 1.556 & 0.997 & 2. 445 & 0.711 & 1. 650 & 1.032 & 0.903 & 1.463 \\
\hline 300 & 0.290 & $0.28 B$ & 0.250 & 1. 504 & 0.956 & 2.335 & 0.669 & 1.580 & a. 986 & 0. 856 & 1. $40 \mathrm{~J}$ \\
\hline 290 & 0.280 & 0.278 & 0.240 & 1. 442 & 0.914 & 2.225 & 0.628 & 1. 509 & a. 939 & 0.809 & I. 339 \\
\hline 280 & a. 270 & 0.268 & 0.230 & 1. 380 & a. 872 & 2.115 & a. 587 & 1. $A 3 B$ & 0.893 & 0.762 & 1. 276 \\
\hline 270 & 0.260 & $0.25 B$ & a. 220 & 1.318 & 0.831 & 2.005 & 0.545 & 1.368 & 0.846 & 0.716 & 1.214 \\
\hline 260 & 0.250 & 0.248 & 0.210 & 1. 256 & 0.789 & 1. 895 & 0.504 & 1.297 & 0.800 & 0.669 & 1. 152 \\
\hline 250 & 0.240 & 0.238 & 0.200 & 1. 195 & 0.747 & 1. 785 & 0.463 & 1.226 & 0.753 & 0.622 & 1.089 \\
\hline 240 & 0.230 & 0.228 & 0.190 & J. 133 & 0.705 & 1.675 & 0.421 & 1. 156 & 0. 707 & 0.575 & 1.027 \\
\hline 230 & 0. 220 & 0.218 & 0.180 & 1.071 & 0.664 & 1. 565 & 0. 380 & 1.085 & 0.660 & 0.528 & 0.965 \\
\hline 220 & 0.210 & 0.208 & 0.170 & 1. 003 & 0.622 & 1. 455 & 0.339 & 1.015 & 0.614 & 0.481 & 0.903 \\
\hline 210 & 0.200 & $0.19 B$ & 0.160 & 0.947 & 0.580 & 1. 345 & 0.297 & 0.944 & 0.567 & 0.434 & 0.840 \\
\hline 200 & 0.190 & 0.188 & 0. 150 & 0.885 & 0.539 & 1. 234 & 0.256 & 0.873 & 0.521 & 0.388 & 0.778 \\
\hline 190 & 0.180 & 0.178 & 0. 140 & 0.823 & 0.497 & I. 124 & 0.215 & 0.803 & a. 474 & 0.341 & 0.716 \\
\hline 180 & 0.170 & 0.168 & 0.130 & 0.761 & 0.455 & 1.014 & 0.173 & 0. 732 & 0.428 & 0.294 & 0. 654 \\
\hline 170 & 0. 160 & 0.158 & 0.120 & 0.699 & 0.413 & 0.904 & 0. 132 & 0.661 & 0.381 & 0.247 & 0.591 \\
\hline 160 & 0. 150 & 0.148 & 0.110 & 0. 637 & 0.372 & a. 794 & 0.091 & 0.591 & 0.335 & 0.200 & 0.529 \\
\hline 150 & 0.140 & 0.138 & 0.100 & 0. 575 & 0.330 & a. $E^{\square A}$ & 0.049 & 0.520 & 0.288 & 0.153 & 0.467 \\
\hline 140 & 0.130 & 0.128 & 0. 090 & 0.513 & 0.288 & 0.574 & n. 0008 & 0.449 & 0.424 & 0.107 & 0.404 \\
\hline
\end{tabular}

由指标 $M$ 的设计思想可以看出， $M>1$ 时,圩内涉水不能按时排至危险程度以下,圩内 农作物 (主要是水穛) 将遭受损失、 $M$ 越大, 洪涉危险程度越大,可能损失也越大。 $M \leqslant 1$ 时,圩区排水能力可将涉水排至安全程度,圩内不受洪。从表 5 中可以看出: $k_{:-1}-1$ 型圩最易受 涉。这也说明有些半山圩由于所处位置较高，圩的建设标准不高，反而易受淽。 $k_{z}-2$ 型圩最 安全。比较他们的分类要紊, $k_{2}-2$ 型圩的排淽模数比 $k_{n-1}-1$ 型大 2.7 倍,这是主要原因。 $k_{2-1}$ 型圩的排港能力不足。还不到排漟标准的下限 $\left(0.0054 \mathrm{~m}^{3} / \mathrm{s} \cdot \mathrm{hm}^{2}\right)$ 。而 $\mathrm{k}_{z^{-}}$型圩的部分抽排 设施将闲置。

从表中还可看出，处于较高位置的半山圩并不比较低位置的平坦圩安全。人类活动已完 全改变了自然的洪涉规律。 


\title{
参考文藏
}

[1] 毛 䌼。太胡大夯与治理太湖。湖泊科学, 1992,4(1), 1-8。

[2] 许正甫。平原扞区治港与内湖综合利用问题。自䧻灾害学报, 1992,1(4), 15-24。

[ 3] 张超等。计量地理学。北京: 亭等教育出版杜。1984:149-161。

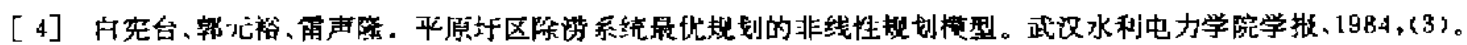

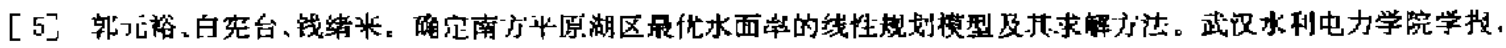
1983.(2).

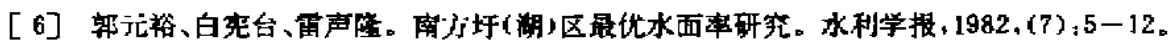

[ 7] 郑篗经主编.太湖水利技术史。北京,农业出版杜。1985。

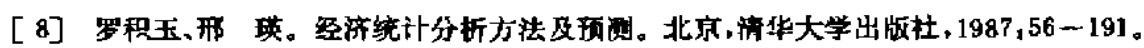

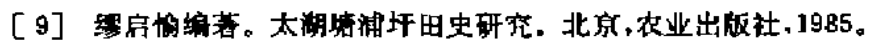

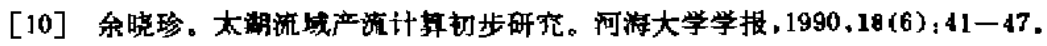

\section{CLASSIFICATION OF POLDERS AND ANALYSIS OF FLOOD - WATERLOGGING IN TAIHU LAKE BASIN - THE CASE OF WEST TAIHU LAKE}

\author{
Gao Junfeng Mao Rui

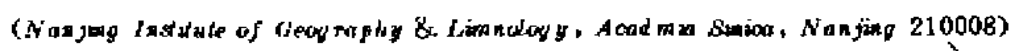

\begin{abstract}
Based on cluster analysis, the polders in west $T$ aihu $L$ ake are classified into eight types. Such key elements to cause flood-waterlogging as rainfall, water surface, elevation, dischange capacity, dyke, topography are analysized. An index $M$ and three-day design rainfall are used to study the flood-waterlogging risk of every type of the polders. The main conclusion is : 1 . Neither all the high lands are safty and nor all the low lands are risky. 2. Human activities have great impacts on flood waterlogging.
\end{abstract}

Key words Polder, classification of polders, flood-waterlogging risk extents 